\title{
$\sigma$-Hole Interactions of Covalently-Bonded Nitrogen, Phosphorus and Arsenic: A Survey of Crystal Structures
}

\author{
Peter Politzer $^{1,2, *}$, Jane S. Murray ${ }^{1,2}$, Goran V. Janjić ${ }^{3}$ and Snežana D. Zarić ${ }^{4,5}$ \\ 1 Department of Chemistry, University of New Orleans, New Orleans, LA 70148, USA; \\ E-Mail: jsmurray@uno.edu \\ 2 CleveTheoComp, 1951 W. 26th Street, Cleveland, OH 44113, USA \\ 3 ICTM, University of Belgrade, Belgrade 11000, Serbia; E-Mail: goran_janjichem@yahoo.com \\ 4 Department of Chemistry, University of Belgrade, Belgrade 11000, Serbia; \\ E-Mail: zaric@mail.chem.tamu.edu \\ 5 Department of Chemistry, Texas A\&M University at Qatar, P.O. Box 23874, Doha, Qatar \\ * Author to whom correspondence should be addressed; E-Mail: ppolitze @ uno.edu; \\ Tel.: +1-202-351-1555.
}

Received: 15 January 2014; in revised form: 24 January 2014 / Accepted: 6 February 2014 /

Published: 26 February 2014

\begin{abstract}
Covalently-bonded atoms of Groups IV-VII tend to have anisotropic charge distributions, the electronic densities being less on the extensions of the bonds ( $\sigma$-holes) than in the intervening regions. These $\sigma$-holes often give rise to positive electrostatic potentials through which the atom can interact attractively and highly directionally with negative sites (e.g., lone pairs, $\pi$ electrons and anions), forming noncovalent complexes. For Group VII this is called "halogen bonding" and has been widely studied both computationally and experimentally. For Groups IV-VI, it is only since 2007 that positive $\sigma$-holes have been recognized as explaining many noncovalent interactions that have in some instances long been known experimentally. There is considerable experimental evidence for such interactions involving groups IV and VI, particularly in the form of surveys of crystal structures. However we have found less extensive evidence for Group V. Accordingly we have now conducted a survey of the Cambridge Structural Database for crystalline close contacts of trivalent nitrogen, phosphorus and arsenic with six different types of electronegative atoms in neighboring molecules. We have found numerous close contacts that fit the criteria for $\sigma$-hole interactions. Some of these are discussed in detail; in two instances, computed molecular electrostatic potentials are presented.
\end{abstract}


Keywords: $\sigma$-hole interactions; trivalent nitrogen; phosphorus and arsenic; survey of crystal structures; electrostatic potentials

\section{The $\sigma$-Hole and Halogen Bonding}

About 20 years ago, while studying the computed electrostatic potentials on the surfaces of halogen-containing molecules, Brinck et al. [1,2] found something totally unexpected: A covalently-bonded halogen often has a region of positive electrostatic potential on its outer side, along the extension of the covalent bond. However the lateral sides of the halogens generally have negative potentials. An example is shown in Figure 1.

Figure 1. Electrostatic potential of bromo-1,3,5-triazine, computed at the B3PW91/6-31G(d,p) level on the molecular surface defined by the 0.001 au contour of the electronic density. The bromine is to the right, coming out of the page; the aromatic ring is to the left, going into the page. Color ranges, in volts, are: red, greater than 0.60 ; yellow, from 0.60 to 0.30 ; green, from 0.30 to 0 ; blue, less than zero (negative). The $\sigma$-hole on the bromine, along the extension of the $\mathrm{C}-\mathrm{Br}$ bond, is shown in red, yellow and green; its most positive value is $0.74 \mathrm{~V}$.

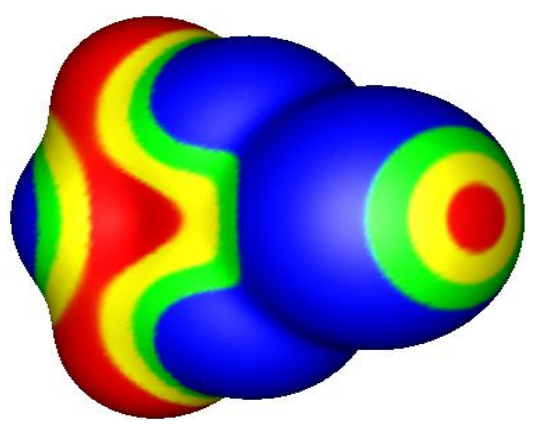

This discovery resolved what had sometimes been called the "enigma" of halogen bonding. It has been known since the mid-19th century that covalently-bonded halogens can form complexes with nitrogen and oxygen Lewis bases, e.g., amines, as well as with other negative sites [3-11]. The enigma was that halogens are considered to usually be negative in character and therefore not anticipated to be attracted to negative sites. The work of Brinck et al. [1,2] provided the explanation. They pointed out, and others subsequently did also [12-14], that halogen bonding can readily be understood as the attractive interaction between the positive outer region on the halogen and the negative site.

This positive region results from the anisotropy of a covalently-bonded halogen's electronic density, which is typically less on the outer side of the halogen (i.e., on the extension of the bond) than on its lateral sides [14-20]. The outer region of lesser electronic density has been labeled a " $\sigma$-hole" [21]. If its electronic density is sufficiently low, then the $\sigma$-hole has a positive electrostatic potential.

Since a $\sigma$-hole arises from the shifting of electronic charge that accompanies the formation of the covalent bond to the halogen, it can be expected that the $\sigma$-hole potential will be more positive as: (a) the halogen is increasingly polarizable $(\mathrm{F}<\mathrm{Cl}<\mathrm{Br}<$ I) and (b) the electron-withdrawing power of the atom or group forming the bond is greater relative to the halogen. These trends have been 
confirmed repeatedly $[10,11,20]$. Thus the halogen $\sigma$-hole is more positive in $\mathrm{C}_{6} \mathrm{H}_{5} \mathrm{Br}$ than in $\mathrm{C}_{6} \mathrm{H}_{5} \mathrm{Cl}$, and more positive in $\mathrm{NC}-\mathrm{Br}$ than in $\mathrm{C}_{6} \mathrm{H}_{5} \mathrm{Br}$ [10]. Fluorine, having the lowest polarizability and highest electronegativity of any halogen, is least likely to have a positive $\sigma$-hole, but it can have one if the remainder of the molecule is sufficiently electron-withdrawing [22-24].

In the context of halogen bonding, a particularly significant series of studies was carried out by Murray-Rust et al. [25-27]. They used the Cambridge Structural Database to survey the crystal structures of numerous halide systems, seeking to identify close intermolecular contacts involving halogens. A close contact was defined as being less than the sum of the respective van der Waals radii, and was interpreted as indicating an attractive noncovalent interaction.

Murray-Rust et al. [25-27] found an interesting pattern. For a halogen $\mathrm{X}$ in a molecule $\mathrm{R}-\mathrm{X}$, its close contacts with nucleophilic components of other molecules were approximately along the extension of the $\mathrm{R}-\mathrm{X}$ bond (structure 1), while those with electrophilic components involved the lateral sides of the halogen (structure 2). These observations are fully consistent with the subsequent demonstration by Brinck et al. [1,2] that many covalently-bonded halogens have positive electrostatic potentials on the extensions of the bonds and negative potentials on their lateral sides. Structure 1 shows what is called a halogen bond; it is characterized by the $\mathrm{R}-\mathrm{X}$---Nucleophile angle being in the neighborhood of $180^{\circ}[10,11,20]$.

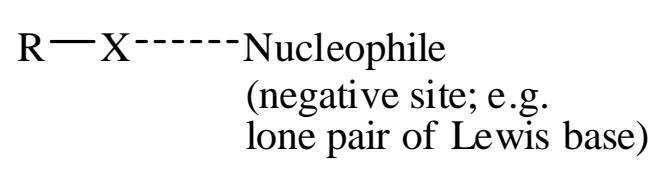

1

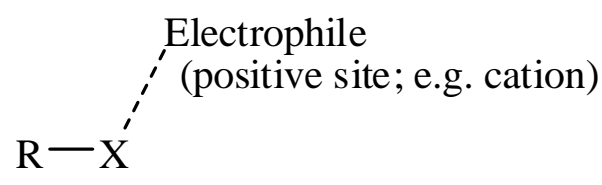

2

Interest in halogen bonding has surged in recent years, due to the recognition of its importance in the design of new materials and in biological systems. There have been several reviews of this work [9,11,20]. An important factor in these applications is the "tunability" of halogen bonding; as discussed above, the magnitude of the positive $\sigma$-hole electrostatic potential (and hence the strength of its interactions) can be modified ("tuned") as desired by varying the halogen and the electron-attracting ability of the remainder of the molecule.

\section{2. $\sigma$-Holes and Groups IV-VI Noncovalent Interactions}

Given the success of the $\sigma$-hole interpretation of halogen bonding, it is natural to inquire: (a) whether covalently-bonded atoms of Groups IV-VI can also exhibit positive $\sigma$-holes; and (b) whether these may account for some of the noncovalent interactions of these atoms and thus be useful in crystal engineering. The answers to both questions are yes.

In a series of computational studies reported between 2007 and 2009 [28-30], it was shown that covalently-bonded atoms of Groups VI, V and IV, respectively, can indeed have regions of positive electrostatic potential on the extensions of the covalent bonds to these atoms. Thus there can be two such regions on atoms of Group VI, three for Group V and four for Group IV (or more if the atoms are hypervalent [30,31]). The existence of these $\sigma$-holes can again be attributed to the anisotropies of the electronic densities of covalently-bonded atoms $[16,19,32,33]$. The magnitudes of the $\sigma$-hole potentials 
are governed by the same factors as for the halogens: They increase in going from the lighter to the heavier (more polarizable) atoms within a Group, and as the partners in the covalent bonds become more electron-withdrawing. The latter factor means that the $\sigma$-holes on a given atom can have different potentials; see Figure 2. Further analyses of what determines the magnitudes of $\sigma$-hole potentials can be found elsewhere [34].

Figure 2. Electrostatic potential of chlorocyanofluorophosphine $[\mathrm{PCl}(\mathrm{CN}) \mathrm{F}]$, computed at the B3PW91/6-31G(d,p) level on the molecular surface defined by the 0.001 au contour of the electronic density. The phosphorus is in the middle, coming out of the page, the cyano group is toward the top, the chlorine to the right and the fluorine to the left. Color ranges, in volts, are: red, greater than 1.1; yellow, from 1.1 to 0.56 ; green, from 0.56 to 0 ; blue, less than zero (negative). There are three $\sigma$-holes on the phosphorus, along the extensions of the $\mathrm{Cl}-\mathrm{P}, \mathrm{F}-\mathrm{P}$ and NC-P bonds; these are shown in red. Their most positive values are: $\mathrm{Cl}-\mathrm{P}, 1.7 \mathrm{~V}$; F-P, $1.5 \mathrm{~V}$; NC-P, $1.4 \mathrm{~V}$.

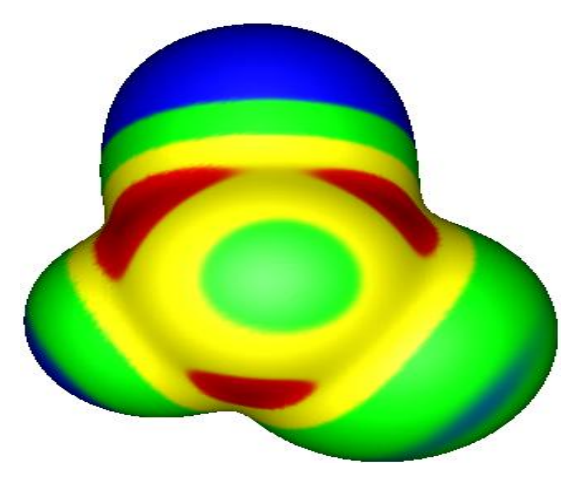

The formation of noncovalent complexes between positive $\sigma$-holes on Groups IV-VI atoms and negative sites has been extensively demonstrated computationally [10,11,20,28-31,35-42] and many such complexes are also known experimentally, in some instances for decades. However, only since 2007 have they been recognized as $\sigma$-hole bonding. Some of this experimental work is now summarized.

Surveys of close contacts in the crystal structures of divalent sulfides [32,43] showed that these follow patterns analogous to what was observed for halides [25-27], mentioned earlier. For a sulfide $\mathrm{R}_{1}-\mathrm{S}-\mathrm{R}_{2}$ close contacts of the sulfur with nucleophilic (negative) sites were approximately along the extensions of the $\mathrm{R}_{1}-\mathrm{S}$ and/or $\mathrm{R}_{2}-\mathrm{S}$ bonds (structure 3 ), while those with electrophilic (positive) sites were above and below the $\mathrm{R}_{1}-\mathrm{S}-\mathrm{R}_{2}$ plane (structure 4 ). Structure 3 clearly depicts a $\sigma$-hole interaction. Selenium close contacts were found to follow similar patterns [33].
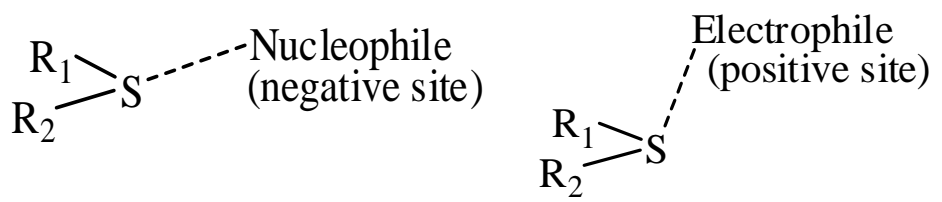

3

One of these studies explicitly drew attention to instances of sulfur in one molecule in close contact with a sulfur in another molecule (structure 5) [32]. Such "like attracting like" can now be understood as the positive $\sigma$-hole on one sulfur interacting with the negative lateral side 
of another. Like-like $\sigma$-hole interactions involving Group V-VII atoms have been found both computationally $[19,20,44,45]$ and experimentally [17,32,46,47], e.g., $\mathrm{ClH}_{2} \mathrm{P}---\mathrm{PH}_{2} \mathrm{Cl}$ [20] and crystalline $\mathrm{Cl}_{2}$ [17]. (In the case of covalently-bonded tetravalent Group IV atoms, we have found that their entire surfaces have positive electrostatic potentials, although the $\sigma$-holes are the most positive [10,20,30]; thus while these atoms do form $\sigma$-hole complexes, they cannot be like-like interactions.)

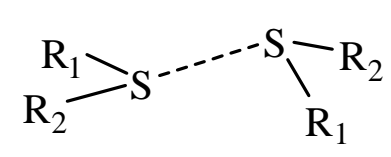

5

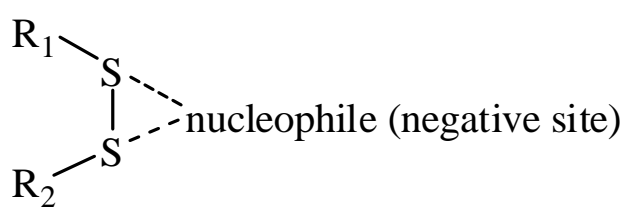

6

A variation of structures $\mathbf{3}$ and $\mathbf{5}$ is the bifurcated structure $\mathbf{6}$, in which the $\sigma$-holes of two linked sulfurs interact with a single nucleophile. This has been found in 315 crystal structures [48].

Numerous S---O close contacts have been observed, some of them as long as 50 years ago [49,50]. These observations were often crystallographically-based, e.g., through surveys of the Cambridge Structural Database [51] and the Protein Data Bank [52]. Neutron diffraction has been used as well [53]. In an interesting analysis by Shishkin et al. [51], an intramolecular S---O $\sigma$-hole bond was suggested to be present in the indigoid dye thioindirubin, purely on the basis of its chemical structure. An S---O close contact was confirmed crystallographically, and the computed electrostatic potential did reveal the $\sigma$-hole interaction.

Particularly notable is a study by Burling and Goldstein [54] involving thiazole and selenazole nucleosides that show a variety of biological activities. The specificities of their binding to a target enzyme depend upon particular conformations being stabilized by intramolecular S---O and Se---O bonding. Burling and Goldstein showed, for the thiazole nucleoside, that these interactions could be explained in terms of positive and negative electrostatic potentials associated with the sulfur and the oxygen, respectively. They were invoking what is now recognized as a positive $\sigma$-hole on the sulfur. (For a relevant later analysis, see Murray et al. [55]).

Se---N $\sigma$-hole interactions were reported in solid $\operatorname{Se}(\mathrm{CN})_{2}$ [56], analogous to what had earlier been predicted computationally for $\mathrm{S}(\mathrm{CN})_{2}$ [28], and $\mathrm{S}---\pi$ interactions have been observed in biological systems [57,58]. Additional experimental examples involving Group VI are cited by Iwaoka et al. [35] and Cozzolino et al. [36].

The experimental evidence of Group V $\sigma$-hole bonding is much less extensive than for Group VI, but it is certainly enough to show that they do occur. There have been observed examples of intramolecular P---P [46,47], P---N [59,60] and P---S [59] close contacts that show the characteristics of $\sigma$-hole interactions; some of the cited examples go back nearly 40 years. A 1991 tabulation of Lewis acids included $\mathrm{PF}_{3}$ and $\mathrm{AsF}_{3}$ [61], indicative of ability to interact with negative sites, e.g., $\mathrm{F}_{3} \mathrm{P}----N u c l e o p h i l e . ~ H i l l ~ e t ~ a l$. [62] describe intermolecular As---Cl interactions.

We are aware of only one systematic survey of Group V crystal structures to find close contacts, and that was limited to trivalent antimony and bismuth compounds [63]. It was found that the great majority of the close contacts were trans to electron-attracting substituents $\mathrm{X}$, i.e., approximately 
along the extensions of the $\mathrm{X}-\mathrm{Sb}$ and $\mathrm{X}-\mathrm{Bi}$ bonds. Such close contacts certainly fit the description of $\sigma$-hole interactions.

There is voluminous research literature dealing with inter- and intra-molecular $\sigma$-hole bonding between tetrahedral Group IV atoms and negative sites [59,64-71]; the latter are often amine nitrogens, but also include others such as oxygens and sulfurs. These complexes are sometimes labeled "bicapped tetrahedra" [64,66,67,69], in order to distinguish them from penta- and hexa-coordination. Kost et al. [69] presented an analysis of the relationships between bicapped tetrahedral and higher-coordinate silicon systems.

Tetrahedral carbon is less likely to participate in $\sigma$-hole interactions than are the other Group IV atoms, because: (a) it is the least polarizable and therefore will have less positive $\sigma$-holes; and (b) it is the smallest, so that the $\sigma$-holes are most likely to be at least partially blocked by the atoms or groups bonded to the carbon. However it was shown already in 2009 that carbon definitely can have positive $\sigma$-holes [30], and stable interactions with negative sites have been demonstrated computationally [42,72].

Banzá et al. [73] conducted a survey of the Cambridge Structural Database for close contacts between tetravalent silicon, germanium or tin and five electronegative atoms (the halogens and oxygen). They found more than 1000 that were less than or equal to the sum of the respective van der Waals radii; however they did not stipulate any directional limitations so it is not known how many of these show the characteristic near-linearity of $\sigma$-hole bonding.

Interesting examples of Group IV intramolecular $\sigma$-hole interactions are provided by $\mathrm{X}$-ray and electron diffraction studies of molecules containing the $\mathrm{Si}-\mathrm{O}-\mathrm{N}$ and $\mathrm{Ge}-\mathrm{O}-\mathrm{N}$ linkages [74-76]. The $\mathrm{Si}-\mathrm{O}-\mathrm{N}$ and $\mathrm{Ge}-\mathrm{O}-\mathrm{N}$ angles were found to be much smaller than would be anticipated. It was later demonstrated computationally that this can be attributed to attractions between silicon and germanium $\sigma$-holes and the nitrogen lone pairs [77].

\section{Present Study}

It is clear from the preceding discussion that surveys of crystal structures have been important sources of experimental evidence for the existence of $\sigma$-hole bonding. Particularly significant were those by Murray-Rust et al. [25-27] and by Parthasarathy et al. [32,33,43], which revealed the different modes of interaction of Group VII and Group VI atoms, respectively, with nucleophiles and with electrophiles. The survey of halogen close contacts in the Protein Data Bank by Auffinger et al. [13] was instrumental in drawing attention to the significance of halogen bonding in biological systems.

To our knowledge, there has been no analogous analysis of crystal data for the first three members of Group V, i.e., nitrogen, phosphorus and arsenic. While there are certainly many specific examples — both experimental [46,47,59,60,62] and computational [20,29,38]—of $\sigma$-hole interactions involving these atoms, it would be useful to have the overall picture that a survey can provide. This is one of our present objectives. We also look in more detail at some individual systems that are uncovered by this survey, focusing upon their electrostatic potentials. 


\section{Survey of Crystal Structures}

We have searched the Cambridge Structural Database (CSD, version 5.34) [78] for near-linear intermolecular close contacts:

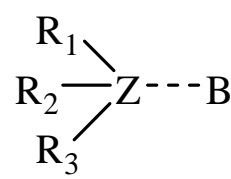

7

where $\mathrm{Z}$ is a trivalent nitrogen, phosphorus or arsenic and $\mathrm{B}$ is a singly-, doubly- or triply-bonded nitrogen $(\mathbf{8}, 9$ or 10), a singly- or doubly-bonded (to carbon) oxygen (11 or 12) or a fluorine (13).

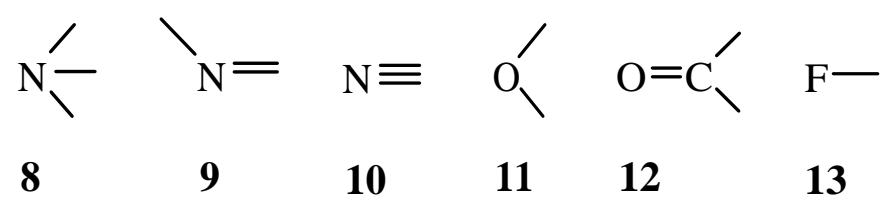

The Quest3D program (version 1.15) [79] was utilized for the search. The crystal structures have $\mathrm{R}<10 \%$ and the error-free coordinates according to the CSD criteria; excluded were polymeric or disordered structures, and those based upon powder patterns.

Our search stipulated that the angle $\mathrm{R}_{2}-\mathrm{Z}---\mathrm{B}$ must be at least $165^{\circ}$ and the $\mathrm{Z}$---B distance no more than $4.0 \AA$. These limits allow minor deviations from exact linearity $\left(180^{\circ}\right)$ and include separations somewhat larger than the sums of the respective van der Waals radii (as shall be seen). Some flexibility in the limits is realistic because the $\sigma$-hole interactions are likely to be affected by various additional intermolecular interactions, especially in a crystal lattice $[24,30,55,80]$. (We return to this later.) It should also be kept in mind that van der Waals radii are not rigorously defined quantities; they are simply approximate and somewhat arbitrary guidelines to noncovalent interactions $[81,82]$, not rigid limits.

In Table 1 is an overall summary of our results. A total of 285 close contacts of the specified types were obtained. Trivalent nitrogen has fewer than either phosphorus or arsenic, which is not surprising; the first-row atoms in Groups IV-VII are known to be less likely than the others to participate in $\sigma$-hole interactions $[10,11,20]$. This can be attributed to them being the most electronegative and least polarizable members of each Group. We now analyze in more detail the types of close contacts that occur most frequently in Table 1.

Table 1. Number of close contacts Z---B of various types.

\begin{tabular}{ccccccc}
\hline $\mathrm{Z}$ & \multicolumn{6}{c}{$\mathrm{B}$} \\
\cline { 2 - 6 } & $\mathrm{N}-(\mathbf{8})$ & $\mathrm{N}^{\prime}=(\mathbf{9})$ & $\mathrm{N} \equiv(\mathbf{1 0})$ & $\mathrm{O}_{\searrow}^{\prime}(\mathbf{1 1})$ & $\mathrm{O}=\mathrm{C}_{\backslash}^{\prime}(\mathbf{1 2})$ & $\mathrm{F}-(\mathbf{1 3})$ \\
\hline $\mathrm{N}$ & 0 & 0 & 0 & 0 & 0 & 13 \\
$\mathrm{P}$ & 16 & 0 & 10 & 43 & 30 & 61 \\
$\mathrm{As}$ & 6 & 0 & 6 & 69 & 5 & 26 \\
\hline
\end{tabular}




\subsection{Close Contacts of Trivalent Phosphorus with Oxygens of Types 11 and 12}

In Figures 3 and 4 are histograms showing the distributions of (a) $\mathrm{P}---\mathrm{O}$ distances and (b) $\mathrm{R}_{2}-\mathrm{P}---\mathrm{O}$ angles in close contacts between trivalent phosphorus atoms and oxygens of type $\mathbf{1 1}$ (Figure 3) or $\mathbf{1 2}$ (Figure 4). Most of the P---O separations are between 3.0 and $3.6 \AA$; the sum of the phosphorus and oxygen van der Waals radii is $3.4 \AA[81,82]$. The $\mathrm{R}_{2}-\mathrm{P}---\mathrm{O}$ angles show the near-linearity that characterizes $\sigma$-hole interactions.

Figure 3. Histograms showing numbers $\mathrm{N}$ of $\mathrm{R}_{2}-\mathrm{P}---\mathrm{O}<$ close contacts at various $\mathrm{P}---\mathrm{O}$ separations (a) and $\mathrm{R}_{2}-\mathrm{P}---\mathrm{O}$ angles $(\mathbf{b})$.

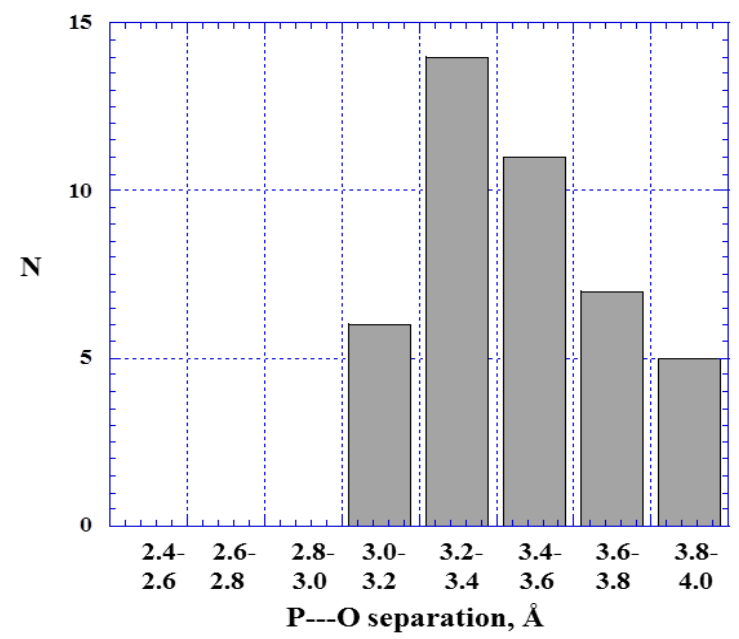

(a)

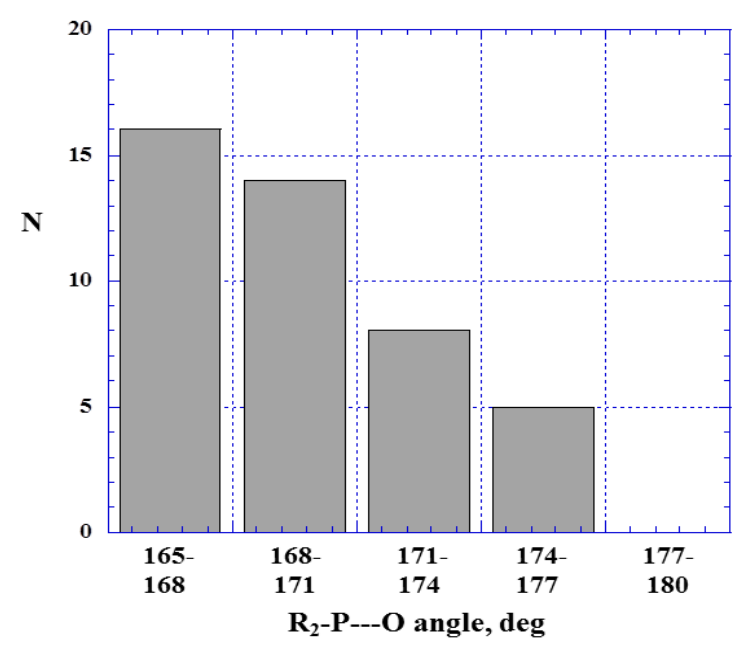

(b)

Figure 4. Histograms showing numbers $\mathrm{N}$ of $\mathrm{R}_{2}-\mathrm{P}---\mathrm{O}=\mathrm{C}<$ close contacts at various $\mathrm{P}---\mathrm{O}$ separations $(\mathbf{a})$ and $\mathrm{R}_{2}-\mathrm{P}---\mathrm{O}$ angles $(\mathbf{b})$.

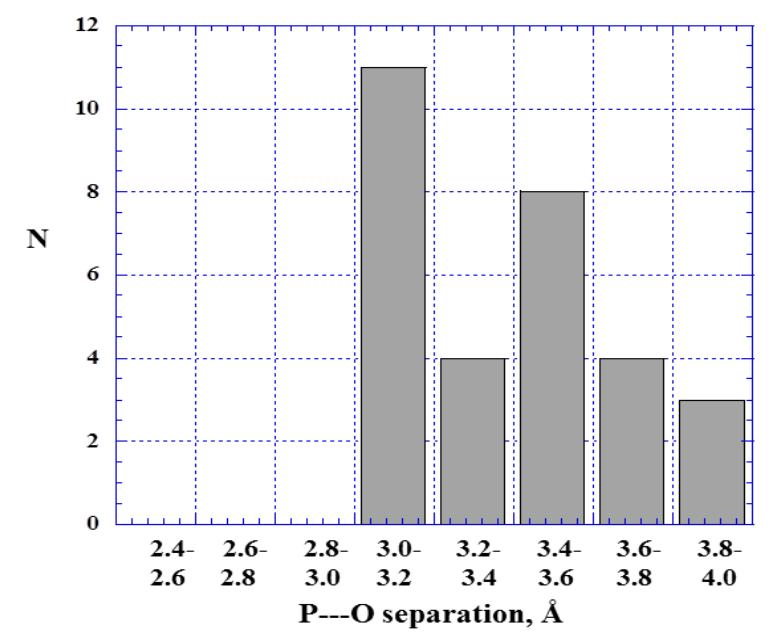

(a)

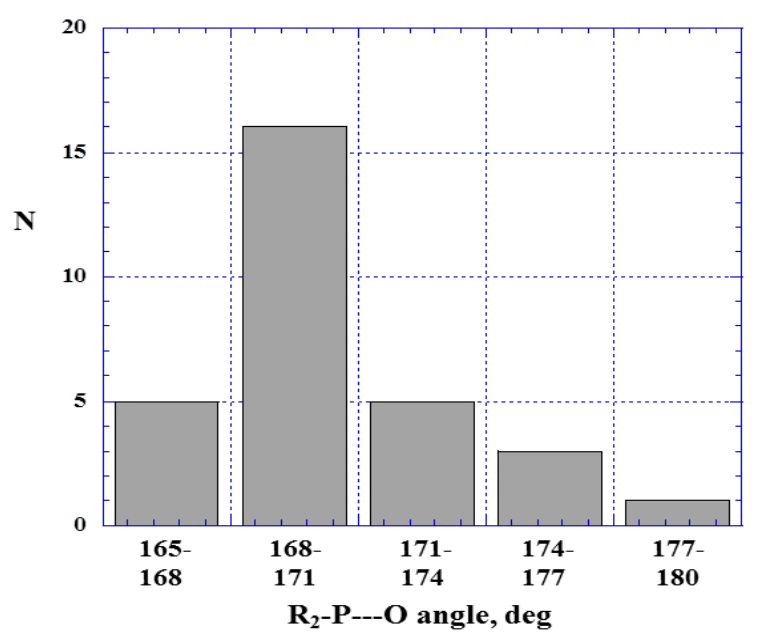

(b)

Comparing Figures 3 and 4 suggests a tendency for the $\mathrm{P}---\mathrm{O}=\mathrm{C}<$ distances to be shorter and the interactions closer to linearity than the $\mathrm{P}---\mathrm{O}<$. One reason for this may be that a doubly-bonded oxygen is more exposed and more accessible, and its interactions less subject to interference, than when the oxygen is bonded to two nearby atoms or groups. 
Particularly in the crystalline state, the likelihood of additional interactions must be considered $[24,30,55,80]$. These can counter the $\sigma$-hole interaction (as is sometimes the case for fluorine $\sigma$-holes [24]) or they may reinforce it. An example of the latter is in Figure 5; the crystal structure of tris(L-alanylmethyl)phosphine tetrahydrate shows $\mathrm{P}---\mathrm{O}=\mathrm{C} \sigma$-hole bonding with $\mathrm{P}-$---O separations of $3.06 \AA[83]$. There are also N-H---O hydrogen bonds, the $\mathrm{H}---\mathrm{O}$ distances ranging from 1.82 to $2.00 \AA$ (the sum of the hydrogen and oxygen van der Waals radii is $2.7 \AA[81,82]$ ).

Figure 5. Fragment of crystal structure of tris(L-alanylmethyl)phosphine tetrahydrate. Colors: red $=$ oxygen, orange $=$ phosphorus, blue $=$ nitrogen, white $=$ hydrogen, gray $=$ carbon.

Dashed lines show $\mathrm{P}---\mathrm{O}=\mathrm{C}$ $\sigma$-hole interactions and $\mathrm{N}-\mathrm{H}---\mathrm{O}$ hydrogen bonds.

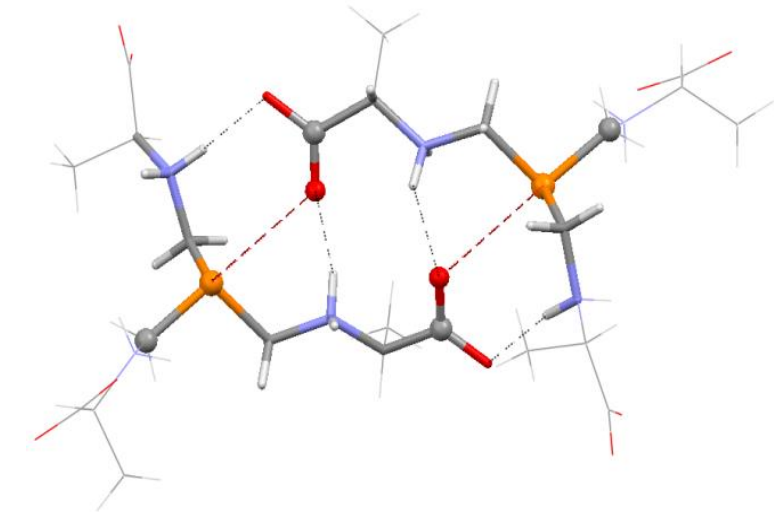

\subsection{Close Contacts of Trivalent Arsenic with Oxygens of Type 11}

The As---O $<$ contacts, Figure 6a, are overall closer than the $\mathrm{P}---\mathrm{O}<$, Figure 3a; the great majority of the As---O< are less than the sum of the arsenic and oxygen van der Waals radii, $3.4 \AA[81,82]$. The shorter As---O $<$ separations compared to the $\mathrm{P}---\mathrm{O}<$ is not surprising; the more polarizable and less electronegative arsenic normally has more positive $\sigma$-holes $[10,11,20,29]$ and therefore should interact more strongly. For example, the $\sigma$-hole on the extension of the $\mathrm{F}-\mathrm{P}$ bond in $\mathrm{H}_{2} \mathrm{FP}$ has a computed maximum positive potential of $1.7 \mathrm{~V}$ and the $\mathrm{H}_{2} \mathrm{FP}---\mathrm{NH}_{3}$ complex has an interaction energy $\Delta \mathrm{E}$ of $-7.2 \mathrm{kcal} / \mathrm{mol}$ [20]; for $\mathrm{H}_{2} \mathrm{FAs}$, the $\mathrm{F}$-As $\sigma$-hole maximum is $1.9 \mathrm{~V}$ and $\Delta \mathrm{E}$ for $\mathrm{H}_{2} \mathrm{FAs}---\mathrm{NH}_{3}$ is $-8.7 \mathrm{kcal} / \mathrm{mol}$. (In this context, it is relevant to mention that both Hartree-Fock and density functional computational procedures have been found to give realistic electrostatic potentials, showing similar trends, provided that split-valence basis sets with polarization functions are used $[34,84,85]$ ).

The shortest As---O distance encountered in our survey of crystal structures was $2.56 \AA$ in the monohydrate of 1-hydroxy-2,1 $\lambda^{5}$-benzoxarsol-3-one (Figure 7) [86]. There is an attractive interaction between the oxygen of the water molecule and the $\sigma$-hole on the extension of an $\mathrm{O}-\mathrm{As}$ bond. There is also a $\mathrm{C}-\mathrm{H}---\mathrm{O}$ hydrogen bond with the water oxygen, the $\mathrm{H}---\mathrm{O}$ separation being $2.46 \AA$ A. Figure 8 displays the computed electrostatic potential on the molecular surface of the arsenic-containing molecule shown in Figure 7; the water molecule is omitted. Clearly visible are the potential maxima of the arsenic $\sigma$-hole, $1.3 \mathrm{~V}$, and of the hydrogen that interacts with the same water oxygen, $1.0 \mathrm{~V}$. 
Figure 6. Histograms showing numbers $\mathrm{N}$ of $\mathrm{R}_{2}-\mathrm{As}---\mathrm{O}<$ close contacts at various As---O separations (a) and $\mathrm{R}_{2}-\mathrm{As}---\mathrm{O}$ angles $(\mathbf{b})$.

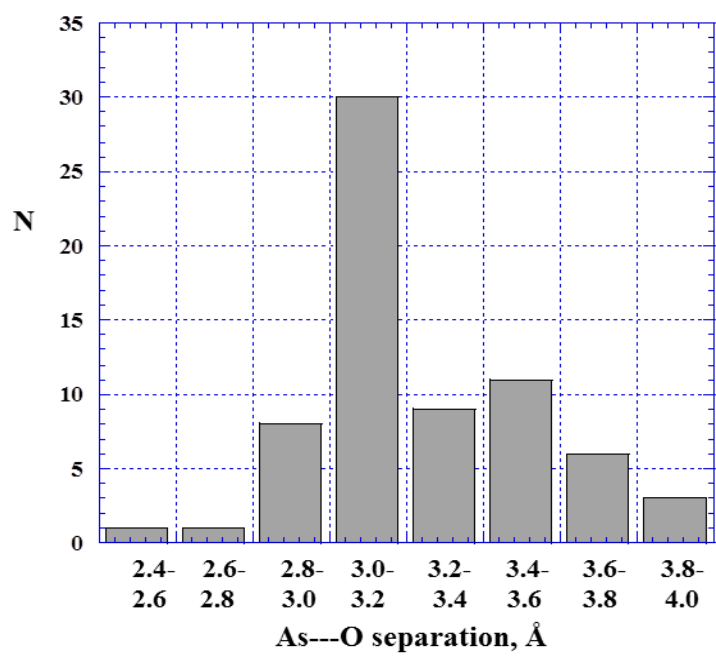

(a)

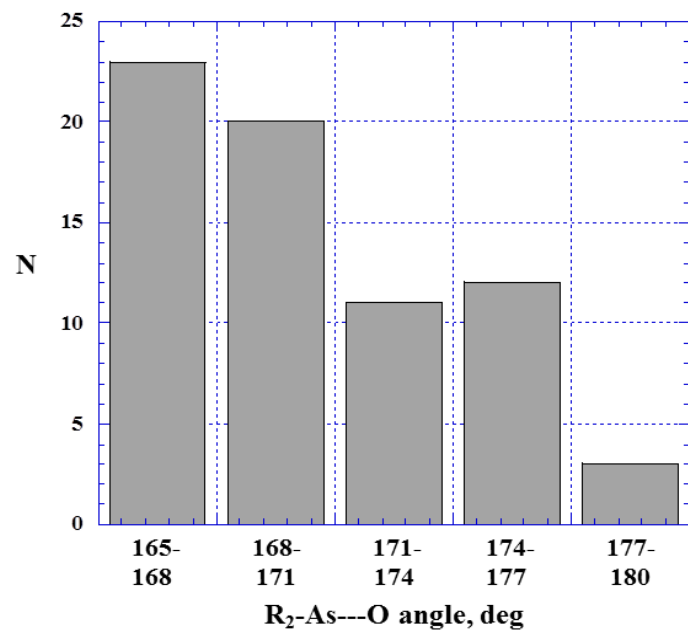

(b)

Figure 7. Fragment of crystal structure of 1-hydroxy-2,1 $\lambda^{5}$-benzoxarsol-3-one monohydrate. Colors: red $=$ oxygen, pink $=$ arsenic, white $=$ hydrogen, gray $=$ carbon. Dashed lines show As---O $\sigma$-hole interaction and $\mathrm{C}-\mathrm{H}---\mathrm{O}$ hydrogen bond.

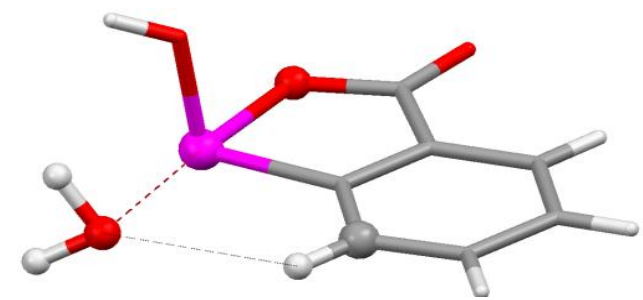

Figure 8. Electrostatic potential of 1-hydroxy-2,1 $1 \lambda^{5}$-benzoxarsol-3-one, computed at the B3PW91/6-31G(d,p) level on the molecular surface defined by the 0.001 au contour of the electronic density. The structure is shown in Figure 7. The arsenic atom is toward the bottom left, the aromatic ring to toward the right, and the hydroxyl group is pointing up. Color ranges, in volts, are: red, greater than 1.1; yellow, from 1.1 to 0.82 ; green, from 0.82 to 0 ; blue, less than zero (negative). One $\sigma$-hole is shown on the arsenic, along the extension of the ring oxygen $\mathrm{O}-\mathrm{As}$ bond; its most positive value is $1.3 \mathrm{~V}$, indicated by a black hemisphere (in red region). The neighboring $\mathrm{C}-\mathrm{H}$ hydrogen, indicated also by a black hemisphere (in yellow region), has a maximum potential of $1.0 \mathrm{~V}$.

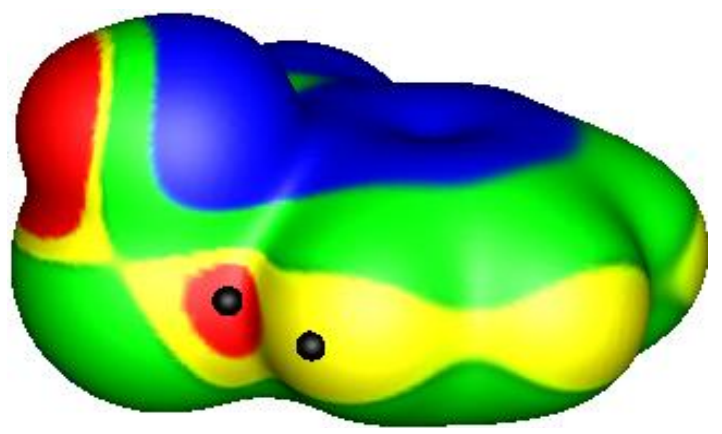




\subsection{Close Contacts of Trivalent Phosphorus with Fluorines}

The P---F- separations tend to be relatively large, Figure 9a, given that the sum of the van der Waals radii is $3.2 \AA[81,82]$. This is consistent with covalently-bonded fluorines often being only weakly negative $[10,22,24,87]$. An interesting case is 5,5-difluoro-4-oxa-5-phosphapentanenitrile, 14. The phosphorus has three positive $\sigma$-holes and in the crystal it interacts simultaneously through two of them with other molecules of $\mathbf{1 4}$ [88], forming what are clearly $\mathrm{P}---\mathrm{F}-$ and $\mathrm{P}---\mathrm{O}<\sigma$-hole bonds (Figure 10); the separations are $3.41 \AA$ and $3.40 \AA$, respectively. In addition, there can be seen C-H---N hydrogen bonding; the H---N distance is $2.68 \AA$, compared to the sum of the hydrogen and nitrogen van der Waals radii, $2.7 \AA[81,82]$.

Figure 9. Histograms showing numbers $\mathrm{N}$ of $1.0 \mathrm{~V}$. ---F- close contacts at various $\mathrm{P}---\mathrm{F}$ separations (a) and $\mathrm{R}_{2}-\mathrm{P}---\mathrm{F}$ angles (b).

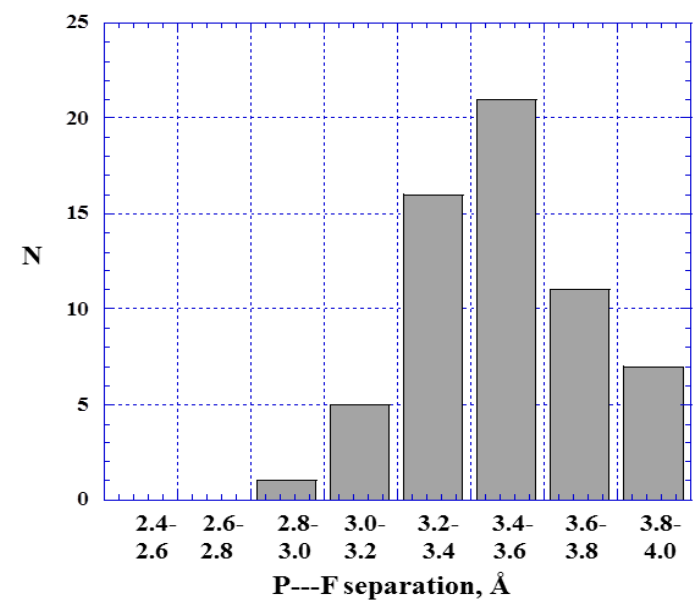

(a)

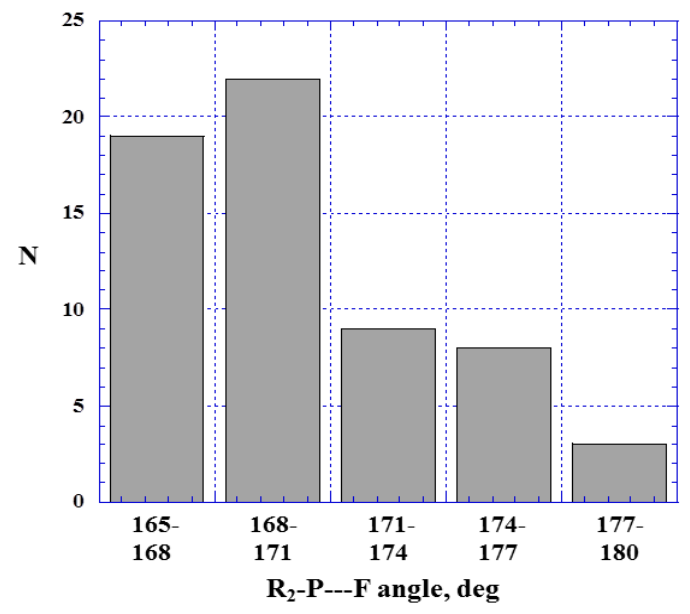

(b)

Figure 10. Fragment of crystal structure of 5,5-difluoro-4-oxa-5-phosphapentanenitrile, 14. Colors: red $=$ oxygen, orange $=$ phosphorus, blue $=$ nitrogen, green $=$ fluorine, white $=$ hydrogen, gray $=$ carbon. Dashed lines show P---F and P---O $\sigma$-hole interactions and $\mathrm{C}-\mathrm{H}---\mathrm{N}$ hydrogen bond.

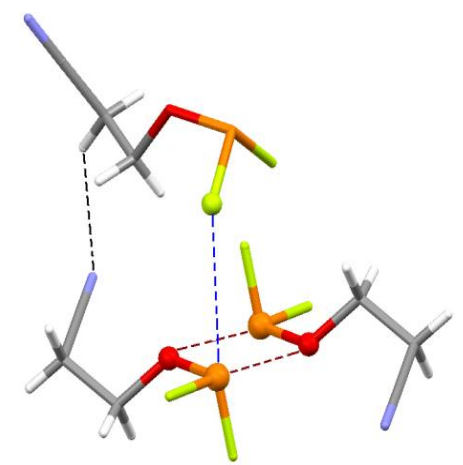

The electrostatic potential on the molecular surface of $\mathbf{1 4}$ is in Figure 11; it shows two of the positive $\sigma$-holes on the phosphorus, on the extensions of the $\mathrm{O}-\mathrm{P}$ and one of the $\mathrm{F}-\mathrm{P}$ bonds. Their potential maxima are 0.95 and $0.82 \mathrm{~V}$, respectively. The most negative potential on the fluorine is a relatively weak $-0.43 \mathrm{~V}$. The computed B3PW91/6-31G(d,p) structure of $\mathbf{1 4}$ used to obtain the 
electrostatic potential in Figure 11 corresponds to the conformation of the molecule in the crystal (as in Figure 10). However a more stable gas phase geometry is obtained both experimentally [88] and computationally by a rotation around the $\mathrm{CH}_{2}-\mathrm{CH}_{2}$ bond. The conformation shown in Figures 10 and 11 allows the observed $\mathrm{C}-\mathrm{H}---\mathrm{N}$ hydrogen bonding as well as the $\mathrm{P}---\mathrm{F}-$ and $\mathrm{P}---\mathrm{O}<\sigma-h o l e$ interactions that are found in the crystal (Figure 10).

Figure 11. Electrostatic potential of 5,5-difluoro-4-oxa-5-phosphapentanenitrile [(NC) $\left.\mathrm{CH}_{2} \mathrm{CH}_{2} \mathrm{OPF}_{2}\right]$, computed at the B3PW91/6-31G(d,p) level on the molecular surface defined by the 0.001 au contour of the electronic density. The phosphorus is toward the lower right, coming out of the page, the cyano group is toward the top, the fluorines are toward the bottom. Color ranges, in volts, are: red, greater than 0.65 ; yellow, from 0.65 to 0.35 ; green, from 0.35 to 0 ; blue, less than zero (negative). Two $\sigma$-holes are shown on the phosphorus in red, along the extensions of the $\mathrm{O}-\mathrm{P}$ and $\mathrm{F}-\mathrm{P}$ bonds. Their most positive values are: O-P, $0.95 \mathrm{~V} ; \mathrm{F}-\mathrm{P}, 0.82 \mathrm{~V}$.

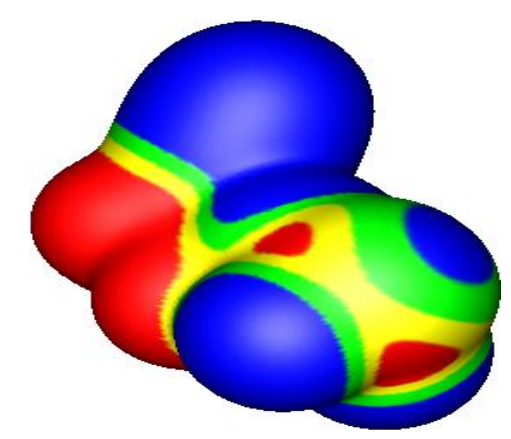

\subsection{Close Contacts of Trivalent Arsenic with Fluorines}

Figure 12a shows that most of the As---F- distances are relatively large compared to the sum of the van der Waals radii, which is $3.3 \AA[81,82]$. As for the P---F-, weakly negative fluorine potentials may often be a factor.

Figure 12. Histograms showing numbers $\mathrm{N}$ of $\mathrm{R}_{2}-\mathrm{As}---\mathrm{F}-$ close contacts at various As---F separations (a) and $\mathrm{R}_{2}-$ As----F angles (b).

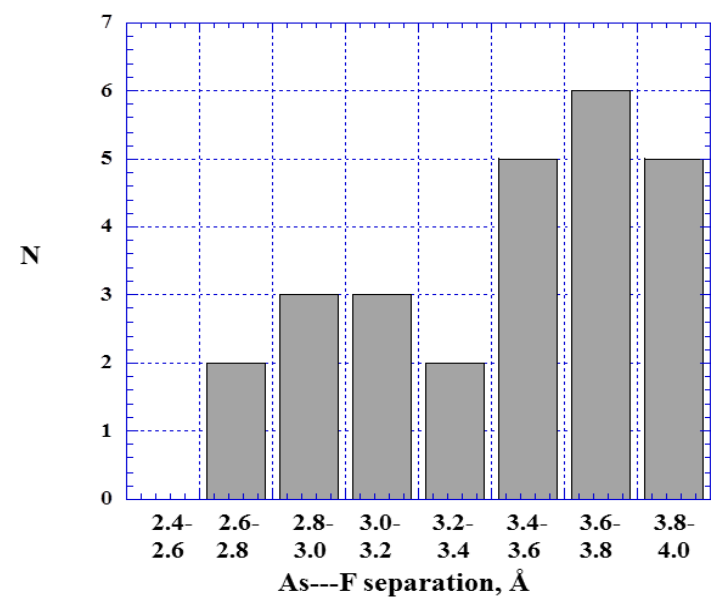

(a)

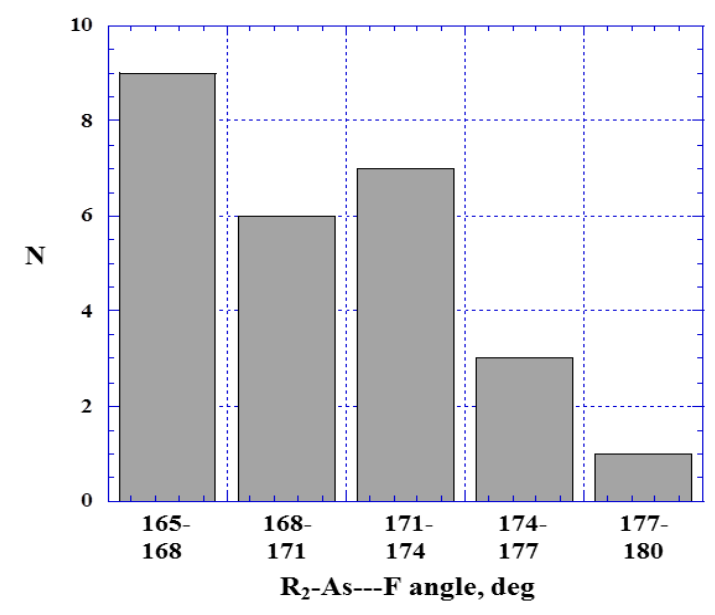

(b) 


\subsection{Close Contacts of Trivalent Nitrogens with Fluorines}

As has been pointed out, the first-row member of each Group usually has the least positive $\sigma$-holes. It can therefore be anticipated that the N---F- interactions will be weaker than the P---F- and As---F-. Indeed, Figure 13a indicates that all of the N---F- contacts are greater than $3.2 \AA$, while the sum of the nitrogen and fluorine van der Waals radii is $3.1 \AA$ [81,82]. It can be inferred that most of these contacts do not represent $\sigma$-hole interactions, especially since their number increases with the N---F separation.

Figure 13. Histograms showing numbers $\mathrm{N}$ of $\mathrm{R}_{2}-\mathrm{N}---\mathrm{F}-$ close contacts at various $\mathrm{N}---\mathrm{F}$ separations (a) and $\mathrm{R}_{2}-\mathrm{N}---\mathrm{F}$ angles (b).

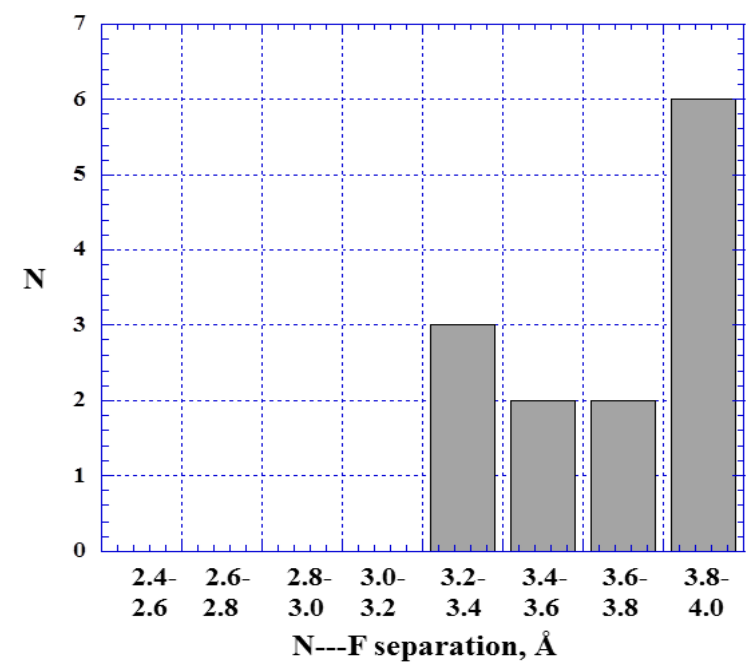

(a)

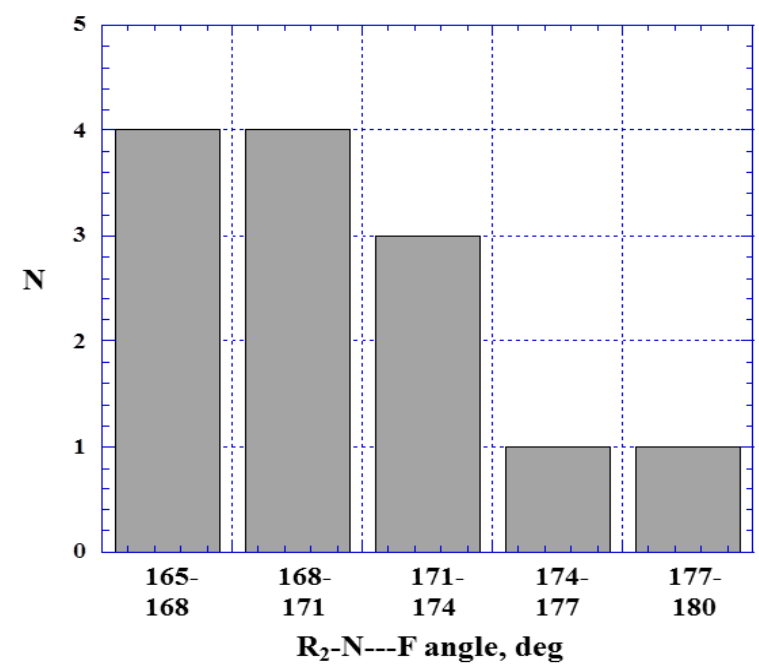

(b)

This does not mean, however, that no nitrogen $\sigma$-hole bonding was found. For example, Figure 14 shows two intermolecular N---F- $\sigma$-hole interactions, with separations of $3.21 \AA$, in the crystal structure of 3,3-bis(difluoroaminomethyl)oxetane [89].

Figure 14. Fragment of crystal structure of 3,3-bis(difluoroaminomethyl)oxetane. Colors: red $=$ oxygen, blue $=$ nitrogen, green $=$ fluorine, white $=$ hydrogen, gray $=$ carbon . Dashed lines show N---F $\sigma$-hole interactions.

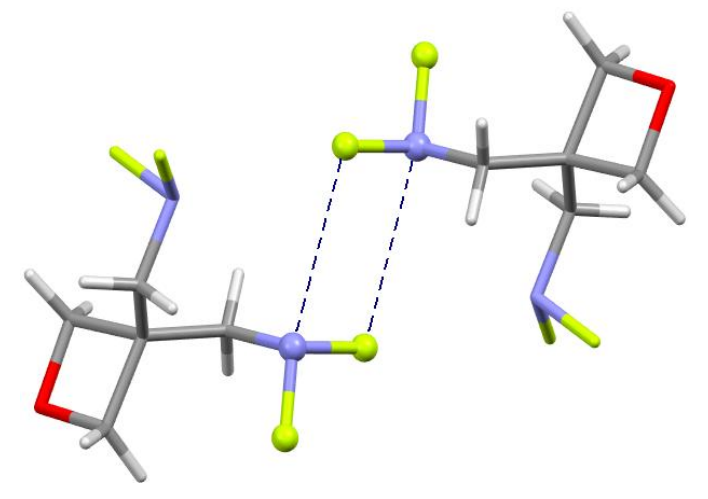




\section{Discussion and Summary}

In analyzing the structures of noncovalent complexes, it is important to be aware that more than one intermolecular (or intramolecular [74-77]) interaction may be occurring [24,30,55,80]. This is particularly likely for Group IV and Group V molecules, in which the atom with the positive $\sigma$-hole is often tetravalent or trivalent, so that there are other atoms or groups in close proximity. This may be true of the negative site as well. These additional interactions may either reinforce or counter the one (or ones) involving a $\sigma$-hole.

As examples of reinforcement, Figures 5, 7 and 10 show hydrogen bonds in addition to $\sigma$-hole interactions, and Figure 10 includes two different types of $\sigma$-hole interactions. In contrast is the gas phase $\mathrm{Cl}_{4} \mathrm{Si}$---NCH complex involving a positive $\sigma$-hole on the silicon and the nitrogen lone pair. A computational study found $\Delta \mathrm{E}=-2.5 \mathrm{kcal} / \mathrm{mol}$, with the $\mathrm{Cl}-\mathrm{Si}$---N angle being $180^{\circ}$ [30]. However the $\mathrm{Si---N}$ separation was $3.93 \AA$, which is $0.2 \AA$ greater than the sum of the silicon and nitrogen van der Waals radii, $3.7 \AA[81,82]$. This was attributed to repulsion between the nitrogen and the chlorines. Riley et al. [80] discuss in detail how the structures of $\sigma$-hole complexes between fluorinated halobenzenes and acetone are affected by intermolecular $\mathrm{H}---\mathrm{F}$ attractions and $\mathrm{H}---\mathrm{H}$ repulsions.

It is with this background that we consider the close contacts summarized in Table 1. Restricting the $\mathrm{R}_{2}-\mathrm{Z}$---B angles to the range $165^{\circ}-180^{\circ}$ ensures that they all have the near-linearity that is characteristic of $\sigma$-hole bonding. Some deviation from exact linearity is to be expected because of the other interactions that are occurring. For instance, in the structure shown in Figure 7, the O-As---O angle of $171.4^{\circ}$ undoubtedly reflects the hydrogen bond in which the water oxygen is also involved. The numerous intermolecular interactions seen in Figures 5 and 10 account for the various $\mathrm{R}_{2}-\mathrm{Z}$---B angles being about $170^{\circ}$.

With respect to the Z---B separations, the sums of the respective van der Waals radii provide some guidelines as to what may be considered close contacts, but they are certainly not rigid. The histograms that we have presented show a significant number of contacts that are less than the sums of the respective van der Waals radii, and they usually have maxima in the vicinities of these sums. The most notable exception is Figure 13, in which the maximum is at relatively large contact distances. Accordingly we interpret only the shortest ones of the N---F- contacts, e.g., Figure 14, as $\sigma$-hole bonding.

Overall, it seems safe to conclude that the majority of the phosphorus and arsenic close contacts in Table 1 do represent $\sigma$-hole interactions. It should also be noted that our survey did not consider all possible negative sites. Other likely ones, in addition to 8-13, include anions, $\pi$ electrons and portions of electronegative atoms such as chlorine and sulfur [11]. Thus, phosphorus and arsenic $\sigma$-hole interactions should be viewed as viable tools for crystal engineering.

\section{Acknowledgments}

This work was supported by the Serbian Ministry of Science (Grant 172065).

\section{Conflicts of Interest}

The authors declare no conflicts of interest. 


\section{References}

1. Brinck, T.; Murray, J.S.; Politzer, P. Surface electrostatic potentials of halogenated methanes as indicators of directional intermolecular interactions. Int. J. Quantum Chem. 1992, 44, 57-64.

2. Brinck, T.; Murray, J.S.; Politzer, P. Molecular surface electrostatic potentials and local ionization energies of group V-VII hydrides and their anions: Relationships for aqueous and gas-phase acidities. Int. J. Quantum Chem. 1993, 48, 73-88.

3. Guthrie, F. XXVIII.-On the iodide of iodammonium. J. Chem. Soc. 1863, 16, 239-244.

4. Prescott, A.B. Notes on a few pyridine alkyl iodides. Am. Chem. J. 1896, 18, 91-96.

5. Hassel, O.; Rømming, C. Direct structural evidence for weak charge transfer bonds in solids containing chemically saturated molecules. Quart. Rev. Chem. Soc. 1962, 16, 1-18.

6. Bent, H.A. Structural chemistry of donor-acceptor interactions. Chem. Rev. 1968, 68, 587-648.

7. Bernard-Houplain, M.-C.; Sandorfy, C. A low temperature infrared study of hydrogen bonding in N-alkylacetamides. Can. J. Chem. 1973, 51, 3640-3647.

8. Di Paolo, T.; Sandorfy, C. On the hydrogen bond breaking ability of fluorocarbons containing higher halogens. Can. J. Chem. 1974, 52, 3612-3622.

9. Metrangolo, P.; Neukirch, H.; Pilati, T.; Resnati, G. Halogen bonding based recognition processes: A world parallel to hydrogen bonding. Acc. Chem. Res. 2005, 38, 386-395.

10. Politzer, P.; Murray, J.S.; Clark, T. Halogen bonding: An electrostatically-driven highly directional noncovalent interaction. Phys. Chem. Chem. Phys. 2010, 12, 7748-7757.

11. Politzer, P.; Murray, J.S. Halogen bonding: An interim discussion. Chem. Phys. Chem. 2013, 14, 278-294.

12. Murray, J.S.; Paulsen, K.; Politzer, P. Molecular surface electrostatic potentials in the analysis of non-hydrogen-bonding noncovalent interactions. Proc. Indian Acad. Sci. Chem. Sci. 1994, 106, 267-275.

13. Auffinger, P.; Hays, F.A.; Westhof, E.; Ho, P.S. Halogen bonds in biological molecules. Proc. Natl. Acad. Sci. 2004, 101, 16789-16794.

14. Awwadi, F.F.; Willett, R.D.; Peterson, K.A.; Twamley, B. The nature of halogen---halogen synthons: Crystallographic and theoretical studies. Chem. Eur. J. 2006, 12, 8952-8960.

15. Stevens, E.D. Experimental electron density distribution of molecular chlorine. Mol. Phys. 1979, $37,27-45$.

16. Nyburg, S.C.; Faerman, C.H. A revision of van der Waals atomic radii for molecular crystals: N, O, F, S, Cl, Se, Br and I bonded to carbon. Acta Cryst. 1985, B41, 274-279.

17. Tsirelson, V.G.; Zou, P.F.; Tang, T.-H.; Bader, R.F.W. Topological definition of crystal structure: Determination of the bonded interactions in solid molecular chlorine. Acta Cryst. A 1995, 51, 143-153.

18. Bilewicz, E.; Rybarczyk-Pirek, A.J.; Dubis, A.T.; Grabowski, S.J. Halogen bonding in crystal structure of 1-methylpyrrol-2-yl trichloromethyl ketone. J. Mol. Struct. 2007, 829, 208-211.

19. Politzer, P.; Riley, K.E.; Bulat, F.A.; Murray, J.S. Perspectives on halogen bonding and other $\sigma$-hole interactions: lex parsimoniae (Occam's Razor). Comput. Theoret. Chem. 2012, 998, 2-8.

20. Politzer, P.; Murray, J.S.; Clark, T. Halogen bonding and other $\sigma$-hole interactions: A perspective. Phys. Chem. Chem. Phys. 2013, 15, 11178-11189. 
21. Clark, T.; Hennemann, M.; Murray, J.S.; Politzer, P. Halogen bonding: The $\sigma$-hole. J. Mol. Model. 2007, 13, 291-296.

22. Politzer, P.; Murray, J.S.; Concha, M.C. Halogen bonding and the design of new materials: Organic bromides, chlorides and even fluorides as donors. J. Mol. Model. 2007, 13, 643-650.

23. Chopra, D.; Guru Row, T.N. Role of organic fluorine in crystal engineering. CrystEngComm 2011, 13, 2175-2186.

24. Metrangolo, P.; Murray, J.S.; Pilati, T.; Politzer, P.; Resnati, G.; Terraneo, G. Fluorine-centered halogen bonding: A factor in recognition phenomena and reactivity. Cryst. Growth Des. 2011, 11, 4238-4246.

25. Murray-Rust, P.; Motherwell, W.D.S. Computer retrieval and analysis of molecular geometry. 4. Intermolecular interactions. J. Am. Chem. Soc. 1979, 101, 4374-4376.

26. Murray-Rust, P.; Stallings, W.C.; Monti, C.T.; Preston, R.K.; Glusker, J.P. Intermolecular interactions of the carbon-fluorine bond: The crystallographic environment of fluorinated carboxylic acids and related structures. J. Am. Chem. Soc. 1983, 105, 3206-3214.

27. Ramasubbu, N.; Parthasarathy, R.; Murray-Rust, P. Angular preferences of intermolecular forces around halogen centers: Preferred directions of approach of electrophiles and nucleophiles around carbon-halogen bonds. J. Am. Chem. Soc. 1986, 108, 4308-4314.

28. Murray, J.S.; Lane, P.; Clark, T.; Politzer, P. $\sigma$-hole bonding: Molecules containing group VI atoms. J. Mol. Model. 2007, 13, 1033-1038.

29. Murray, J.S.; Lane, P.; Politzer, P. A predicted new type of directional interaction. Int. J. Quant. Chem. 2007, 107, 2286-2292.

30. Murray, J.S.; Lane, P.; Politzer, P. Expansion of the $\sigma$-hole concept. J. Mol. Model. 2009, 15, 723-729.

31. Clark, T.; Murray, J.S.; Lane, P.; Politzer, P. Why are dimethyl sulfoxide and dimethyl sulfone such good solvents? J. Mol. Model. 2008, 14, 689-697.

32. Guru Row, T.N.; Parthasarathy, R. Directional preferences of nonbonded atomic contacts with divalent sulfur in terms of its orbital orientations. 2. S---S interactions and nonspherical shape of sulfur in crystals. J. Am. Chem. Soc. 1981, 103, 477-479.

33. Ramasubbu, N.; Parthasarathy, R. Stereochemistry of incipient electrophilic and nucleophilic reactions at divalent selenium center: Electrophilic-Nucleophilic pairing and anisotropic shape of Se in Se---Se interactions. Phosphorus Sulfur 1987, 31, 221-229.

34. Murray, J.S.; Macaveiu, L.; Politzer, P. Factors affecting the strengths of $\sigma$-hole electrostatic potentials. J. Comput. Sci. 2014, doi:10.1016/j.jocs.2014.01.002.

35. Iwaoka, M.; Komatsu, H.; Katsuda, T.; Tomoda, S. Quantitative evaluation of weak nonbonded Se---F interactions and their remarkable nature as orbital interactions. J. Am. Chem. Soc. 2002, 124, 1902-1909.

36. Cozzolino, A.F.; Vargas-Baca, I.; Mansour, S.; Mahmoudkhani, A.H. The nature of the supramolecular association of 1,2,5-chalcogenadiazoles. J. Am. Chem. Soc. 2005, 127, 3184-3190.

37. Bleiholder, C.; Werz, D.B.; Köppel, H.; Gleiter, R. Theoretical investigations on chalcogen-chalcogen interactions: What makes these nonbonded interactions bonding? J. Am. Chem. Soc. 2006, 128, 2666-2674. 
38. Mohajeri, A.; Pakiari, A.H.; Bagheri, N. Theoretical studies on the nature of bonding in $\sigma$-hole complexes. Chem. Phys. Lett. 2009, 467, 393-397.

39. Zhao, Q.; Feng, D.; Sun, Y.; Hao, J.; Cai, Z. Theoretical investigations on the weak nonbonded $\mathrm{C}=\mathrm{S}---\mathrm{CH}_{2}$ interactions: Chalcogen-based complexes with singlet carbene as an electron donor. Int. J. Quantum Chem. 2011, 111, 3881-3887.

40. Jing, B.; Li, Q.; Gong, B.; Li, R.; Liu, Z.; Li, W.; Cheng, J.; Sun, J. Hydrogen bond and $\sigma$-hole interaction in $\mathrm{M}_{2} \mathrm{C}=\mathrm{S}---\mathrm{HCN}\left(\mathrm{M}=\mathrm{H}, \mathrm{F}, \mathrm{Cl}, \mathrm{Br}, \mathrm{HO}, \mathrm{H}_{3} \mathrm{C}, \mathrm{H}_{2} \mathrm{~N}\right)$ complex: Dual roles of $\mathrm{C}=\mathrm{S}$ group and substitution effects. Int. J. Quantum Chem. 2012, 112, 1491-1498.

41. Li, Q.-Z.; Li, R.; Guo, P.; Li, H.; Li, W.-Z.; Cheng, J.-B. Competition of chalcogen bond, halogen bond and hydrogen bond in SCS---HOX and SeCSe---HOX $(\mathrm{X}=\mathrm{Cl}$ and $\mathrm{Br})$ complexes. Comput. Theor. Chem. 2012, 980, 56-61.

42. Bundhun, A.; Ramasami, P.; Murray, J.S.; Politzer, P. Trends in $\sigma$-hole strengths and interactions of $\mathrm{F}_{3} \mathrm{MX}$ molecules $(\mathrm{M}=\mathrm{C}, \mathrm{Si}$, Ge and X = F, Cl, Br, I). J. Mol. Model. 2013, 19, 2739-2746.

43. Rosenfield, R.E., Jr.; Parthasarathy, R.; Dunitz, J.D. Directional preferences of nonbonded atomic contacts with divalent sulfur. 1. Electrophiles and nucleophiles. J. Am. Chem. Soc. 1977, 99, 4860-4862.

44. Politzer, P.; Murray, J.S.; Concha, M.C. $\sigma$-Hole bonding between like atoms: A fallacy of atomic charges. J. Mol. Model. 2008, 14, 659-665.

45. Politzer, P.; Murray, J.S. Molecular Electrostatic Potentials: Some Observations. In Concepts and Methods in Modern Theoretical Chemistry, Vol. 1: Electronic Structure and Reactivity; Ghosh, K., Chattaraj, P., Eds.; Taylor \& Francis: New York, NY, 2013; Chapter 9, pp. 181-199.

46. Widhalm, M.; Kratky, C. Synthesis and X-ray structure of binaphthyl-based macrocyclic diphosphanes and their Ni(II) and Pd(II) complexes. Chem. Ber. 1992, 125, 679-689.

47. Sundberg, M.R.; Uggla, R.; Viñas, C.; Teixidor, F.; Paavola, S.; Kivekäs, R. Nature of intramolecular interactions in hypercoordinate C-substituted 1,2-Dicarba-closo-dodecaboranes with short P-P distances. Inorg. Chem. Commun. 2007, 10, 713-716.

48. Zhang, Y.; Wang, W. The bifurcate chalcogen bond: Some theoretical observations. J. Mol. Struct. Theochem. 2009, 916, 135-138.

49. Mammi, M.; Bardi, R.; Traverso, G.; Bezzi, S. Crystal structure of 2,5-dimethyl-dithio-furophthene, a homologue of thio-thiophthene. Nature 1961, 192, 1282-1283.

50. Lynch, T.R.; Mellor, I.P.; Nyburg, S.C.; Yates, P. The structure and stereochemistry of the desaurin from acetophenone. Tetrahedron Lett. 1967, 373-377.

51. Shishkin, O.V.; Omelchenko, I.V.; Kalyuzhny, A.L.; Paponov, B.V. Intramolecular S---O chalcogen bond in thioindirubin. Struct. Chem. 2010, 21, 1005-1011.

52. Junming, L.; Yunxiang, L.; Subin, Y.; Weiliang, Z. Theoretical and crystallographic data investigations of noncovalent S---O interactions. Struct. Chem. 2011, 22, 757-763.

53. Cohen-Addad, C.; Lehmann, M.S.; Becker, P.; Párkányi, L.; Kálmán, A. Nature of S---O interaction in short $\mathrm{X}-\mathrm{S}---\mathrm{O}$ contacts: Charge density experimental studies and theoretical interpretation. J. Chem. Soc. Perkin Trans. II 1984, 191-196.

54. Burling, F.T.; Goldstein, B.M. Computational studies of nonbonded sulfur-oxygen and selenium-oxygen interactions in the thiazole and selenazole nucleosides. J. Am. Chem. Soc. 1992, $114,2313-2320$. 
55. Murray, J.S.; Lane, P.; Politzer, P. Simultaneous $\sigma$-hole and hydrogen bonding by sulfur- and selenium-containing heterocycles. Int. J. Quantum Chem. 2008, 108, 2770-2781.

56. Klapötke, T.M.; Krumm, B.; Scherr, M. Homoleptic selenium cyanides: Attempted preparation of $\mathrm{Se}(\mathrm{CN})_{4}$ and redetermination of the crystal structure of $\mathrm{Se}(\mathrm{CN})_{2}$. Inorg. Chem. 2008, 47, 7025-7028.

57. Viguera, A.R.; Serrano, L. Side-chain interactions between sulfur-containing amino acids and phenylalanine in $\alpha$-helixes. Biochemistry 1995, 34, 8771-8779.

58. Tatko, C.D.; Waters, M.L. Investigation of the nature of the methionine- $\pi$ interaction in $\beta$-hairpin peptide model systems. Protein Sci. 2004, 13, 2515-2522.

59. Carré, F.; Chuit, C.; Corriu, R.J.P.; Monforte, P.; Nayyar, N.K.; Reyé, C. Intramolecular coordination at phosphorus: Donor acceptor interaction in three- and four-coordinated phosphorus compounds. J. Organometall. Chem. 1995, 499, 147-154.

60. Tschirschwitz, S.; Lönnecke, P.; Hey-Hawkins, E. Aminoalkylferrocenyldichloro-phosphanes: Facile synthesis of versatile chiral starting materials. Dalton Trans. 2007, 14, 1377-1382.

61. Drago, R.S.; Wong, N.; Ferris, D.C. The E, C, T interpretation of bond dissociation energies and anion-neutral molecule interactions. J. Am. Chem. Soc. 1991, 113, 1970-1977.

62. Hill, N.J.; Levason, W.; Reid, G. Arsenic (III) halide complexes with phosphine and arsine Co-ligands: Synthesis, spectroscopic and structural properties. J. Chem. Soc. Dalton Trans. 2002, 1188-1192.

63. Starbuck, J.; Norman, N.C.; Orpen, A.G. Secondary bonding as a potential design element for crystal engineering. New J. Chem. 1999, 23, 969-972.

64. Brellère, C.; Carré, F.; Corriu, R.J.P.; Poirier, M.; Royo, G.; Zwecker, J. Hexacoordinated silicon species: A possible model for reaction intermediates. 1. X-ray determination of the geometry in the solid state. Organometallics 1989, 8, 1831-1833.

65. Carré, F.; Chuit, C.; Corriu, R.J.P.; Mehdi, A.; Reye, C. Synthesis, structure and fluxional behavior of a dihydrosilane bearing an aryldiamine pincer ligand. Organometallics 1995, 14, 2754-2759.

66. Belzner, J.; Schär, D.; Herbst-Irmer, R.; Kneisel, B.O.; Noltemeyer, M. Synthesis and structure of silicon compounds intramolecularly coordinated to hydrazino groups. Tetrahedron 1998, 54, 8481-8500.

67. Ahdab, A.A.-E.; Rima, G.; Gornitzka, H.; Barrau, J. Synthesis and Characterization of 2,4,6-tris((dimethylamino)methyl)phenoxysilicon compounds. J. Organomet. Chem. 2001, 636, 96-107.

68. Berceanc, V.; Crainic, C.; Haiduc, I.; Mahon, M.F.; Molloy, K.C.; Venter, M.M.; Wilson, P.J. The structural chemistry of organotin derivatives of 5-Mercapto-3-Phenyl-1,3,4-thiadiazoline-2-thione: Supramolecular structures involving intermolecular $\mathrm{Sn}---\mathrm{S}, \mathrm{N}-\mathrm{H}---\mathrm{S}$ or $\mathrm{S}---\mathrm{S}$ interactions. J. Chem. Soc. Dalton Trans. 2002, 6, 1036-1045.

69. Kost, D.; Gostevskii, B.; Kalikhman, I. Silicon rehybridization and molecular rearrangements in hypercoordinate silicon dichelates. Pure Appl. Chem. 2007, 79, 1125-1134.

70. Cheng, F.; Hector, A.L.; Levason, W.; Reid, G.; Webster, M.; Zhang, W. Preparation and structure of the unique silicon (IV) cation $\left[\mathrm{SiF}_{3}\left(\mathrm{Me}_{3} \mathrm{tacn}\right)\right]^{+}$. Chem. Commun. 2009, 1334-1336.

71. Shainyan, B.A.; Lazareva, N.F. $\mathrm{P}=\mathrm{O} \rightarrow \mathrm{Si}$ intramolecular coordination in the derivatives of 1,4-phosphasilacyclohexane 1-oxides. Int. J. Quantum Chem. 2009, 109, 301-307. 
72. Grabowski, S.J. Tetrel-bond $\sigma$-hole bond as a preliminary stage of the $\mathrm{S}_{\mathrm{N}} 2$ reaction. Phys. Chem. Chem. Phys. 2014, 16, 1824-1834.

73. Banzá, A.; Mooibroek, T.J.; Frontera, A. Tetrel-bonding interaction: Rediscovered supramolecular force? Angew. Chem. Int. Ed. 2013, 52, 12317-12321.

74. Mitzel, N.W.; Blake, A.J.; Rankin, D.W.H. $\beta$-donor bonds in SiON units: An inherent structure determining property leading to $(4+4)$-coordination in tetrakis-(N,N-dimethylhydroxylamido)silane. J. Am. Chem. Soc. 1997, 119, 4143-4148.

75. Losehand, U.; Mitzel, N.W.; Rankin, D.W.H. Synthesis and molecular structures of N,N-dimethylhydroxylamino-trichlorosilane and -germane. J. Chem. Soc. Dalton Trans. 1999, 4291-4297.

76. Mitzel, N.W.; Vojinovic, K.; Froehlich, R.; Foerster, T.; Robertson, H.E.; Borisenko, K.B.; Rankin, D.W.H. Three-membered ring or open chain molecule- $\left(\mathrm{F}_{3} \mathrm{C}\right) \mathrm{F}_{2} \mathrm{SiONMe}_{2}$ a model for the $\alpha$-effect in silicon chemistry. J. Am. Chem. Soc. 2005, 127, 13705-13713.

77. Murray, J.S.; Concha, M.C.; Politzer, P. Molecular surface electrostatic potentials as guides to Si-O-N angle contraction: Tunable $\sigma$-holes. J. Mol. Model. 2011, 17, 2151-2157.

78. Allen, F.H. The cambridge structural database: A quarter of a million crystal structures and rising. Acta Cryst. 2002, B58, 380-388.

79. Bruno, I.J.; Cole, J.C.; Edgington, P.R.; Kessler, M.; Macrae, C.F.; Cabe, P.M.; Pearson, J.; Taylor, R. New software for searching the cambridge structural database and visualizing crystal structures. Acta Cryst. 2002, B58, 389-397.

80. Riley, K.E.; Murray, J.S.; Fanfrlík, J.; Řezáč, J.; Solá, R.J.; Concha, M.C.; Ramos, F.M.; Politzer, P. Halogen bond tunability I: The effects of aromatic fluorine substitution on the strengths of halogen-bonding interactions involving chlorine, bromine and iodine. J. Mol. Model. 2011, 17, 3309-3318.

81. Bondi, A. Van der Waals Volumes and Radii. J. Phys. Chem. 1964, 68, 441-451.

82. Rowland, R.S.; Taylor, R. Intermolecular nonbonded contact distances in organic crystal structures: Comparison with distances expected from van der Waals Radii. J. Phys. Chem. 1996, 100, 7384-7391.

83. Raghuraman, K.; Katti, K.K.; Barbour, L.J.; Pillarsetty, N.; Barnes, C.L.; Katti, K.V. Characterization of supramolecular $\left(\mathrm{H}_{2} \mathrm{O}\right)_{18}$ water morphology and water-methanol $\left(\mathrm{H}_{2} \mathrm{O}\right)_{15}\left(\mathrm{CH}_{3} \mathrm{OH}\right)_{3}$ clusters in a novel phosphorus functionalized trimeric amino acid host. J. Am. Chem. Soc. 2003, 125, 6955-6961.

84. Bulat, F.A.; Toro-Labbé, A.; Brinck, T.; Murray, J.S.; Politzer, P. Quantitative analysis of molecular surfaces: Areas, volumes, electrostatic potentials and average local ionization energies. J. Mol. Model. 2010, 16, 1689-1691.

85. Murray, J.S.; Politzer, P. The electrostatic potential: An overview. WIREs Comp. Mol. Sci. 2011, $1,153-163$.

86. Hundal, M.S.; Hundal, G.; Parmar, S.S. 1-Hydroxy-2,1 $1 \lambda^{5}$-benzoxarsol-3-one monohydrate. Acta Cryst. 1996, C52, 2726-2728.

87. Politzer, P.; Murray, J.S.; Concha, M.C. The complementary roles of molecular surface electrostatic potentials and average local ionization energies with respect to electrophilic processes. Int. J. Quantum Chem. 2002, 88, 19-27. 
88. Blake, A.J.; Davis, M.J.; Rankin, D.W.H. Instant ligands: Part 5. The molecular structures of $\left(\mathrm{PF}_{2}\right) \mathrm{OCH}_{2} \mathrm{C} \mathrm{CCH}_{2} \mathrm{O}\left(\mathrm{PF}_{2}\right)$ in the gas phase and $\mathrm{PF}_{2} \mathrm{OCH}_{2} \mathrm{CH}_{2} \mathrm{CN}$ in gaseous and crystalline phases. J. Mol. Struct. 1990, 221, 25-44.

89. Gilardi, R.; Evans, R.N.; Manser, G.E. 3,3-bis(difluoroaminomethyl)oxetane, a promising new energetic material. Acta Cryst. 2003, E59, o2032-o2034.

(C) 2014 by the authors; licensee MDPI, Basel, Switzerland. This article is an open access article distributed under the terms and conditions of the Creative Commons Attribution license (http://creativecommons.org/licenses/by/3.0/). 